\title{
This Is an Experiment: Capturing the Everyday Dynamics of Collaboration in The Diary Room
}

\section{Felicity Callard, Des Fitzgerald and Kimberley Staines}

\begin{abstract}
In this chapter, Felicity Callard, Des Fitzgerald and Kimberley Staines invite the reader to join an experiment they designed specially for The Hub at Wellcome Collection and ran there for a number of months. 'In the Diary Room' provides a space and setting for collaborators to reflect on how they think and feel about interdisciplinary collaboration. The reader is encouraged to join an experiment that gathers together an archive tracking the rhythms, energies, detritus and restlessness of interdisciplinary labour.
\end{abstract}

Keywords Reflexivity · Emotion · Experimental · Interdisciplinarity · Video

We would like to add you to our list of participants. ${ }^{1}$ Are you interested? You can say no if you like. You've been working in The Hub, this smoothly

F. Callard $(\bowtie) \cdot$ K. Staines

Durham University, Durham, United Kingdom

e-mail: felicity.callard@durham.ac.uk; staines.kimberley@gmail.com

D. Fitzgerald

Cardiff University, Cardiff, Wales, United Kingdom

e-mail: FitzgeraldP@cardiff.ac.uk

(C) The Author(s) 2016 


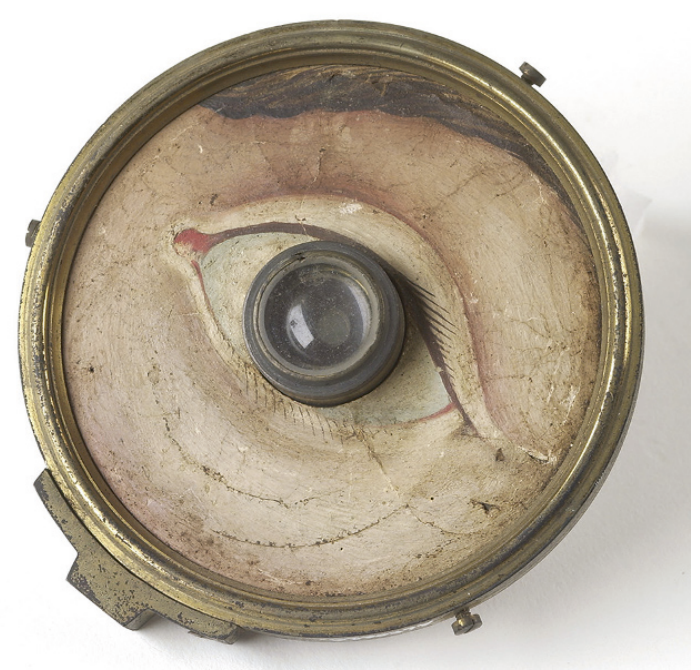

Fig. 19.1 Model eye, glass lens with brass-backed paper front with hand-painted face around eye, by W. and S. Jones, London, 1840-1900. (Credit: Wellcome Library, London, Wellcome Images L0035463, released under a Creative Commons Attribution only licence 4.0 International License (CC BY 4.0))

contoured space for interdisciplinary collaboration, for some time. We would love a few more participants for our experiment that's trying to understand its rhythms, to capture the practices of interdisciplinarity in the making. ${ }^{2}$

Once you're on the list, you might - at any time - be called with a ring of a bell. We'll call you during Hub office hours - you won't be required outside the regular working day. ${ }^{i}$ There's also a technical system that we've devised to randomize whom we call, and on what days and times. Sometimes, though, as with most experiments, we need to make slight adjustments - tinker a little bit with our protocol. ${ }^{3}$ That might affect how frequently you are called.

If yours is the name on the white board when the bell sounds, we ask you to come as soon as you can to the Diary Room. It's easy to find: It's

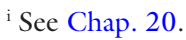




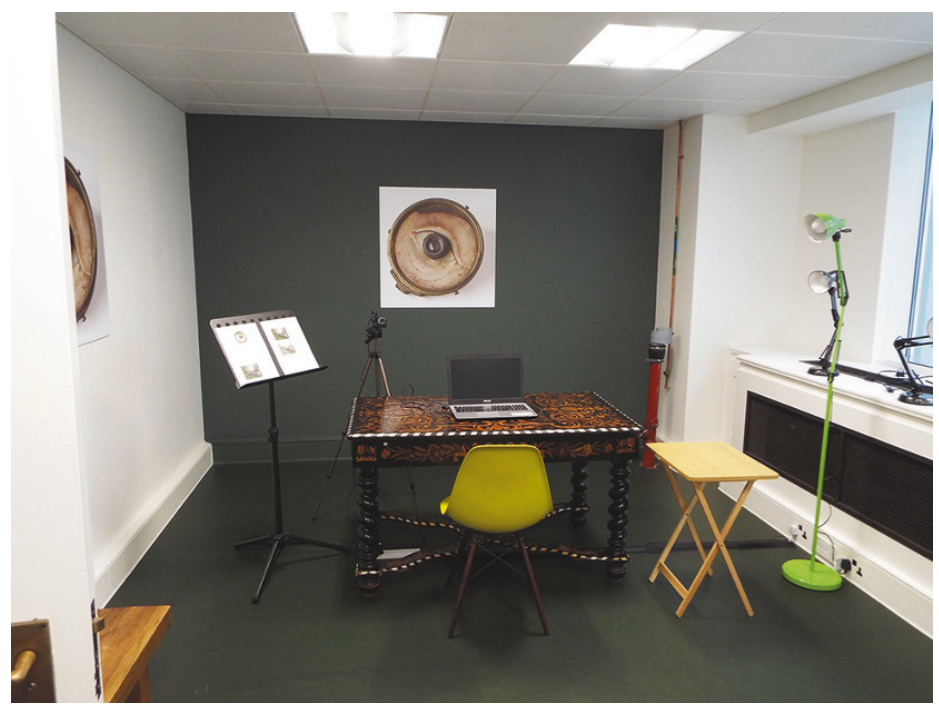

Fig. 19.2 The Diary Room awaits a visitor. (Credit: Kimberley Staines. Background artwork: see Fig. 19.1.)

the only door featuring a nineteenth-century model eye. ${ }^{4}$ Is the eye part of the experimental assemblage? We're not sure. You can decide for yourself (Fig. 19.1).

Once you open the door, you'll find a standard lap-top, an old carved desk (Henry Wellcome's desk, some say), a music stand and a low-end video camera. You'll be alone. The music stand contains a series of instructions about what you need to do. They're designed to be comprehensible even if you're not feeling particularly technologically proficient. (We checked: we can operate them.) We think these props could function pretty much anywhere. All that's needed is a quiet space with a door that closes for privacy (Fig. 19.2).

We've put all the details on the information sheet, but here it is in a nutshell: Open the lap-top and turn on the camera, load the programme, indicate if you still consent; if so, you'll be asked a series of five, randomized questions; each is spoken out loud, by a disembodied voice, which issues from the computer. Just speak into the computer to respond (Fig. 19.3). 


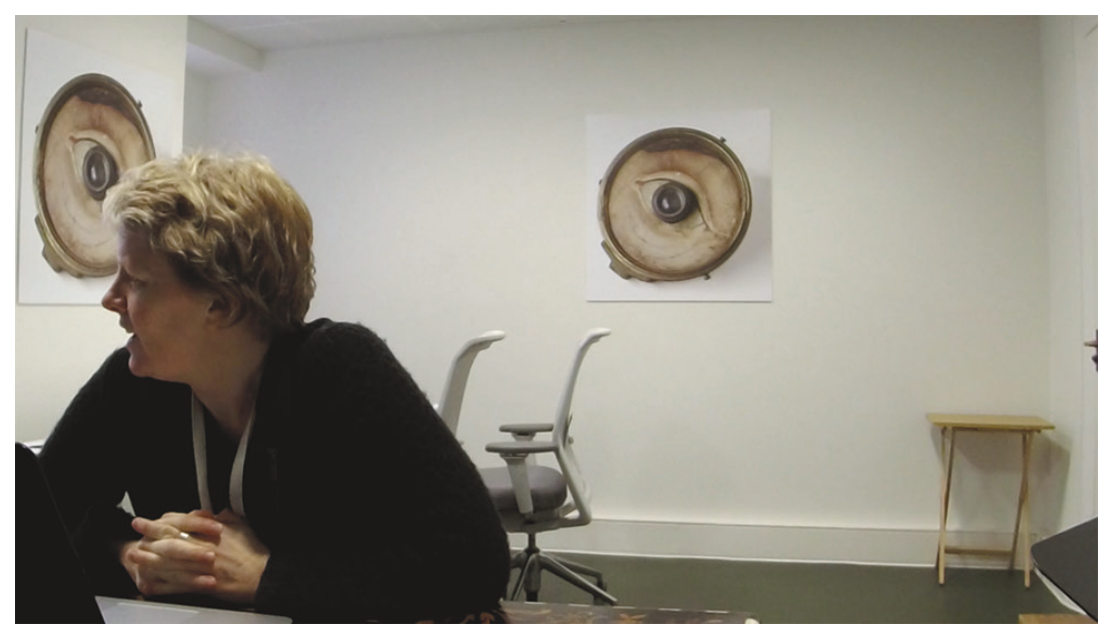

Fig. 19.3 An interview in process. Footage of participants is captured wherever they settle, and the DIY nature of The Diary Room undermines any attempts at controlling composition of the recordings. (Credit: Kimberley Staines. Background artwork: see Fig. 19.1.)

The questions are about interdisciplinarity and collaboration. Our wish is to test a novel method for gathering self-reflexive data on interdisciplinary collaboration as it happens, by generating a database of participants' thoughts - spontaneous, unpractised - about Hubbub during the course of the project. When we were making our Diary Room, we distinguished between our serious and our banal prompts. But now we're not so sure. It might be that your response to 'What did you have for lunch? Or what are you hoping to have for lunch?' might be just as useful in opening up the dynamics of collaboration as your response to a more self-consciously important enquiry (such as 'Do you think the physical space of the Hub facilitates collaboration?’).

You might recognize a voice that asks you a question. All are spoken by staff employed by our funder. We came up with the questions, and we asked people to lend us their voices - which they kindly did. These voices, unexpectedly, add a layer of complexity that you may notice: who

ii See Chap. 16. 


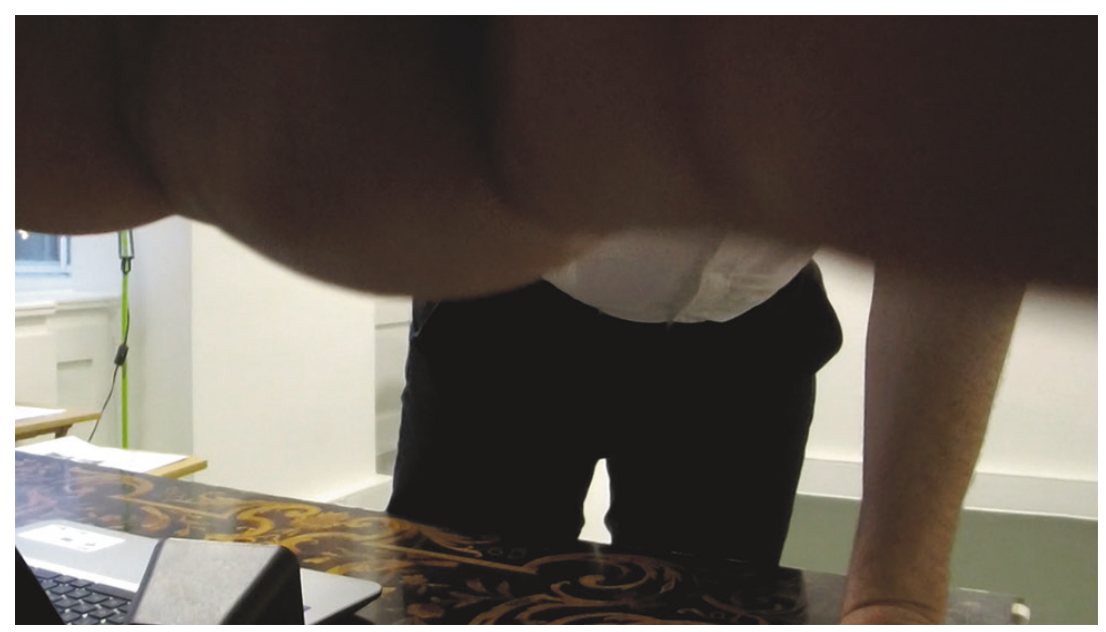

Fig. 19.4 A participant begins filming an interview in The Diary Room (Credit: Kimberley Staines)

is actually speaking in this temporally and spatially loaded interplay of voice, identity and recording device? Who are they speaking to? For what reason? ?ii $^{\mathrm{i}}$

We would like you to sit in a way that ensures you're captured on the video screen. (We review the footage gathered only after the project has ended. No one will consider your responses in vivo.) We would like to record your gestures, as well as hear your voice. The camera might also capture how you settle yourself after you've turned it on, as well as how you move towards it to switch it off. Usually, one would dispense with moments that are not part of the main action, but we would like to think about these movements too. We are trying not to decide in advance what is signal and what is noise (Fig. 19.4).

Some of the questions we ask are probably boring. Boredom - a common feature of research studies across the social sciences - is, we think, an under-investigated aspect of experimental design. ${ }^{5}$ And so it's quite possible you might become bored, or disgruntled, or irritated. Who knows how those feelings might contour your responses? And remember: You can withdraw your consent and leave at any time. 
You might want to know what this is about. We're interested in tracking the mundane intimacies of collaboration. We're interested in the noisy, restive work of doing an interdisciplinary project, as well as in following the energies of the people and things invested in it. We're also interested in the network of stimulus, setting and participant, which circulates through the experiment, its tools and its setting. We're interested in how practices that get called 'creative' and 'scholarly' might get disrupted together. We're interested in you, in how your day has gone, in what you've been up to, in how you reflect on it, in what you think is happening here, anyway. And we're interested, finally, in novel practices: in displacing the tools and rhetorics of disciplinary process; in rethinking how we produce and gather data; in finding new ways to talk about what it is we've been up to; in doing something that's maybe a bit more of an experiment.

Acknowledgements We are grateful to all participants in 'In the Diary Room' and to the Wellcome Trust staff who recorded questions for us. We thank Johannes Golchert, for his work on coding the 'In the Diary Room' programme, and Charlotte Sowerby, who did so much to manage the dynamics of day-to-day experiment.

\section{Notes}

1. This piece reports on - and describes - 'In the Diary Room' (ItDR), a project which received ethics approval from the Research Ethics Geography Committee at Durham University, and whose material is being used in both scholarly and artistic outputs. In keeping with the experimental and creative spirit of ItDR, what follows is a way of thinking about what the project is up to, told through one (of many possible) modes of description and via one particular mode of address to the reader. For the avoidance of doubt, what follows is a faithful description of what we have done in ItDR, but the address to the reader as a potential participant is a fictional device.

2. Felicity Callard, Des Fitzgerald, and Angela Woods, 'Interdisciplinary Collaboration in Action: Tracking the Signal, Tracing the Noise', Palgrave Communications 1 (2015): 15,019.

3. On tinkering, see Hans-Jörg Rheinberger, Toward a History of Epistemic Things: Synthesizing Proteins in the Test Tube (Stanford, Calif.: Stanford University Press, 1997).

4. All details for the model eye are available at Wellcome Images: https:// wellcomeimages.org (search under L0035463). Credit: Wellcome Library, London Model eye, glass lens with brass-backed paper front with handpainted face around eye, by W. and S. Jones, London, 1840-1900. 
Photograph. Collection: Wellcome Images. Library reference no.: Museum No. A680620. Available under the terms of the Creative Commons Attribution 4.0 International License (http://creativecommons.org/ licenses/by/4.0/).

5. We are intrigued by how scientific daydreaming and mind wandering experiments have frequently involved the production of monotonous situations; for example, see Jerome L. Singer, Daydreaming and Fantasy (London: Allen and Unwin, 1976).

Felicity Callard is Director of Hubbub and an academic at Durham University (Department of Geography and Centre for Medical Humanities). Her interdisciplinary research focuses on the history and present of psychiatry, psychology, psychoanalysis and the neurosciences. She is co-author of Rethinking Interdisciplinarity across the Social Sciences and Neurosciences (Palgrave Macmillan, 2015).

Des Fitzgerald is a sociologist at Cardiff University. He is a sociologist of science and medicine, with a particular interest in the history and present of the neurosciences. He is co-author of Rethinking Interdisciplinarity across the Social Sciences and Neurosciences (Palgrave Macmillan, 2015).

Kimberley Staines is Project Coordinator of Hubbub (Durham University). She has a background in law and publishing, is a Master's student in Psychosocial Studies at Birkbeck, University of London, and a trustee of a food bank in London.

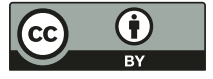

This chapter is distributed under the terms of the Creative Commons Attribution 4.0 International License (http://creativecommons.org/ licenses/by/4.0/), which permits use, duplication, adaptation, distribution and reproduction in any medium or format, as long as you give appropriate credit to the original author(s) and the source, a link is provided to the Creative Commons license and any changes made are indicated.

The images or other third party material in this chapter are included in the work's Creative Commons license, unless indicated otherwise in the credit line; if such material is not included in the work's Creative Commons license and the respective action is not permitted by statutory regulation, users will need to obtain permission from the license holder to duplicate, adapt or reproduce the material. 